\title{
Synthesis of Macrocyclic Bis-Hydrazone and Their Use in Metal Cations Extraction
}

\author{
Farouk Kandil, Mohamad Khaled Chebani, and Wail Al Zoubi \\ Department of Chemistry, Faculty of Science, University of Damascus, Damascus, Syria \\ Correspondence should be addressed to Wail Al Zoubi, wwailalzoubi@yahoo.com \\ Received 9 October 2011; Accepted 30 October 2011 \\ Academic Editor: G. Li
}

Copyright () 2012 Farouk Kandil et al. This is an open access article distributed under the Creative Commons Attribution License, which permits unrestricted use, distribution, and reproduction in any medium, provided the original work is properly cited.

Two new macrocyclic hydrazone Schiff bases were synthesized by reaction of succindihydrazide and adipdihydrazide with acetylacetone. Hydrazones have been characterized by elemental analyses and IR, mass, ${ }^{1} \mathrm{H} N M R$, and ${ }^{13} \mathrm{C}$ NMR spectral data. Hydrazones have been studied by liquid-liquid extraction towards the s-metal ions $\left(\mathrm{Li}^{+}, \mathrm{Na}^{+}\right.$, and $\left.\mathrm{K}^{+}\right)$and $\mathrm{d}$-metal ions $\left(\mathrm{Cu}{ }^{2+}\right.$ and $\mathrm{Cr}^{3+}$ ) from aqueous phase to organic phase. The effect of chloroform and dichloromethane as organic solvents over the metal chlorides extraction was investigated at $25 \pm 0.1^{\circ} \mathrm{C}$ by using flame atomic absorption. We found differences between the two solvents in extraction selectivity.

\section{Introduction}

Hydrazones are special class of compounds in the Schiff bases family. They are characterized by the presence of the following

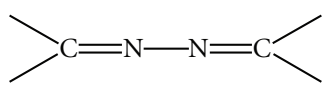

Hydrazone Schiff bases of acyl, aroyl, and heteroaroyl compounds have an addition donor sites like $\mathrm{C}=\mathrm{O}$. The additional donor sites make them more flexible and versatile. This versatility has made hydrazones good polydentate chelating agents that can form a variety of complexes with various transition and inner transition metals and have attracted the attention of many researchers [1].

A wide varieties of hydrazones and their metal complexes have been studied because of their important properties which can be used in different applications, such as, extraction of some metal ions [2], microdetermination of metal ions [2], determination of titanium in bauxite, Portland cement, amphibolites granites [3], and different biological activities, such as antimicrobial [2, 4-7], antifungal [8, 9], antitumor $[10,11]$, and insecticides [12]. For these applications, we are extending this field of compounds for synthesising novel macrocyclic hydrazones.
Five dissymmetric tridentate Schiff base ligands containing a mixed donor set of ONN and ONO were prepared by the reaction of benzohydrazide with the appropriate salicylaldehyde and pyridine-2-carbaldehyde and characterized by FT-IR, ${ }^{1} \mathrm{H}$ NMR, and ${ }^{13} \mathrm{C}$ NMR [13].

Inoue et al. [14] reported the synthesis and spectroscopic characterization of complexes of $\mathrm{Ni}^{2+}, \mathrm{Cu}^{2+}, \mathrm{Zn}^{2+}$, and $\mathrm{Cd}^{2+}$ with hydrazones Schiff bases derived from 6-amino-5formyl-1,3-dimethyluracil, nicotinic and isonicotinic acids hydrazides. Avaji et al. [15] reported the synthesis and characterization of a macrocyclic hydrazone Schiff bases prepared by condensation of 1,4-dicarbonyl phenyl dihydrazide with 2,6-diformyl-4-methyl phenol. Emara et al. reported [16-18] formation of binuclear complexes for the ligands derived from 4,6-diacetylresorcinol, where the ligands were prepared by condensation of 4,6-diacetylresorcinol (DAR) with oxalyldihydrazine $(\mathrm{ODH})$ in the molar ratios $(1: 1)$ and $(1: 2)$ to afford the corresponding hydrazone, $\mathrm{H}_{6} \mathrm{La}$ and $\mathrm{H}_{4} \mathrm{Lb}$, ligands, respectively. Otomo and Nakayama et al. [19] reported formation of three terdentate hydrazones, all containing the 1-phthalazino grouping in the hydrazine moiety but differing in the heterocyclic substituent in the aldehyde moiety, where the ligands were used as analytical reagents for palladium(II), the optimal conditions for the extractive spectrophotometric determination of palladium(II) in the presence of chloride ions being deduced. These compounds 


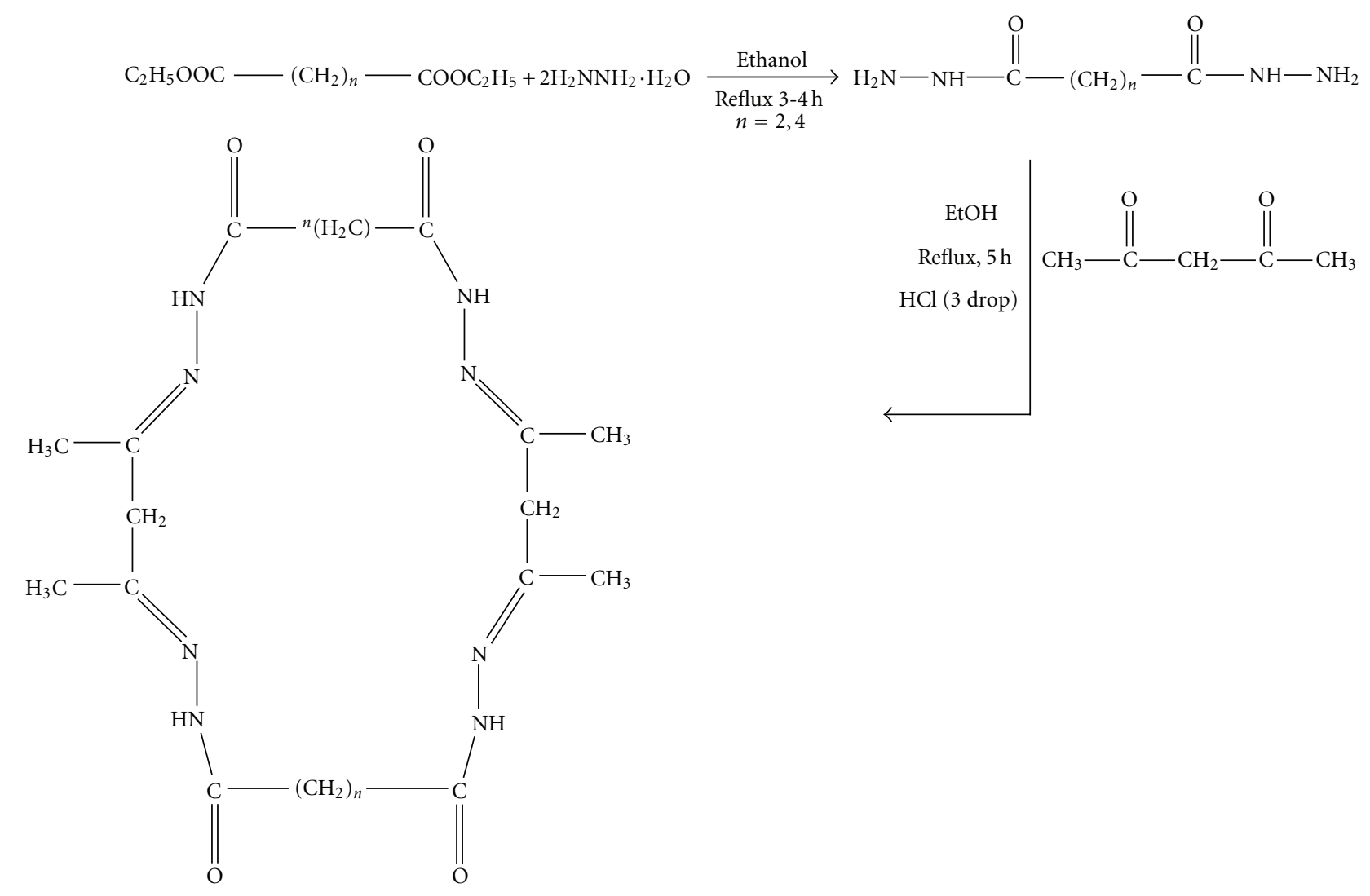

Scheme 1: Synthesis of macrocyclic hydrazone Schiff bases.

were highly selective and sensitive reagents for palladium(II), since they were not extracted into chloroform from sulfuric acid solutions and did not react with other platinum group metals. Odashima and Ishii [20] reported the synthesis and spectroscopic characterization of four new hydrazones, 2-pyridinecarbaldehyde 3-nitro-2-pyridylhydrazone, 2-pyridinecarbaldehyde 3,5-dinitro-2-pyridylhydrazone (PA-3,5$\mathrm{NPH}$, 2-quinolinecarbaldehyde 5-nitro-2-pyridylhydrazone, and 6-phenanthridinecarbaldehyde 5-nitro-2-pyridylhydrazone. Also useful information on the molecular design of the hydrazone reagent was obtained. A highly sensitive and practical extraction-spectrophotometric method for the determination of nickel with PA-3,5-NPH developed and applied successfully to the determination of nickel in steel samples.

In the context of the above applications, we have reported here the synthesis and characterization of novel macrocyclic hydrazone Schiff bases and their extraction study of some transition metal cations. The structure of Schiff bases and scheme synthesis is shown in Scheme 1.

\section{Experimental}

2.1. Reagents and Apparatus. All the chemicals used were of AnalaR grade and procured from Sigma-Aldrich and Fluka. Metal salts were purchased from E. Merck and were used as received. Distilled water was used in extraction experimentals. The solvents were saturated with each other before use in order to prevent volume changes of the phases during extraction.

The C, H, and $\mathrm{N}$ were analyzed on a Carlo-Erba 1106 elemental analyzer. The IR spectra was recorded on Jusco 300 instrument in $\mathrm{KBr}$ pellets. ${ }^{1} \mathrm{H}$ and ${ }^{13} \mathrm{C}-\mathrm{NMR}$ spectra of ligands in $\mathrm{CDCl}_{3}$ solution were recorded on a Bruker DT$400 \mathrm{MHz}$ spectrometer, and chemical shifts are indicated in ppm relative to tetramethylsilane. Mass spectra were recorded using a KRATOS MS50TC spectrometer.

AA 929 Unicam Spectrometer was used for FAAS measurements with an air-acetylene flame. A pH meter (Metrohm 691 pH Meter) was also used. All extractions experiments were performed by using a mechanical flask agitator in $50 \mathrm{~cm}^{3}$ stoppered glass flasks.

2.2. Synthesis of Diethyl Succinate. A succinic acid $(9.19 \mathrm{mmol})$ in absolute dry ethanol $(60 \mathrm{~mL})$ containing 2-3 drops of concentrated $\mathrm{H}_{2} \mathrm{SO}_{4}$ was refluxed, continuing the heating for 20-30 minutes. When the reflux time is complete, remove the flask from the heating mantle, allow it to cool briefly. Then, the reaction mixture was poured onto ice cold water. Place about $5 \mathrm{~mL}$ chipped ice in a 50 -mL beaker and mix it with $15 \mathrm{~mL} 10 \%$ aqueous $\mathrm{Na}_{2} \mathrm{CO}_{3}$ (sodium carbonate) (the $\mathrm{pH}$ should be above 7 . If it is not, add more 
(10\%) $\mathrm{Na}_{2} \mathrm{CO}_{3}$ dropwise until the solution is basic). The ester thus obtained was extracted by diethyl ether. Then dry the ether solution in the centrifuge tube by adding several spatula-tip loads of anhydrous $\mathrm{Na}_{2} \mathrm{SO}_{4}$ [17].

2.3. Synthesis of Diethyl Adipate. Adipic acid $(7.92 \mathrm{mmol})$ in absolute dry ethanol $(60 \mathrm{~mL})$ containing 2-3 drops of concentrated $\mathrm{H}_{2} \mathrm{SO}_{4}$ was refluxed, then continue the heating for 20-30 minutes. When the reflux time is complete, remove the flask from the heating mantle, allow it to cool briefly. Then, the reaction mixture was poured onto ice cold water. Place about $5 \mathrm{~mL}$ chipped ice in a $50-\mathrm{mL}$ beaker and mix it with $15 \mathrm{~mL} 10 \%$ aqueous $\mathrm{Na}_{2} \mathrm{CO}_{3}$ (sodium carbonate)(the $\mathrm{pH}$ should be above 7. If it is not, add more $10 \% \mathrm{Na}_{2} \mathrm{CO}_{3}$ dropwise until the solution is basic). The ester thus obtained was extracted by diethyl ether. Then dry the ether solution in the centrifuge tube by adding several spatula-tip loads of anhydrous $\mathrm{Na}_{2} \mathrm{SO}_{4}$ [17].

2.4. Synthesis of Succinic Acid Dihydrazide. Mixture of diethyl ester of succinic acid $(2.22 \mathrm{~g})$ and hydrazine hydrate $(98 \%$ $2 \mathrm{cc})$ in ethanol $(80 \mathrm{~mL})$ was refluxed for $4-5 \mathrm{~h}$. The reaction mixture was allowed to cool in room temperature, then the cooled solution was poured onto ice cold water. The dihydrazide of Succinic acid thus obtained was filtered and recrystallized from ethanol.

2.5. Synthesis of Dihydrazide of Adipic Acid Dihydrazide. A mixture of diethyl ester of adipic acid $(2.22 \mathrm{~g})$ and hydrazine hydrate $(98 \% 2 \mathrm{cc})$ in ethanol $(80 \mathrm{~mL})$ was refluxed for 4 $5 \mathrm{~h}$. The reaction mixture was allowed to cool in room temperature, then the cooled solution was poured onto ice cold water. The dihydrazide of adipic acid obtained was filtered and recrystallized from ethanol.

2.6. Synthesis of Macrocyclic Succinic Acid Hydrazone Ligand $(I)$. The hot ethanolic solution $(20 \mathrm{~mL})$, of acetylacetone $(2 \mathrm{mmol}, 0.2 \mathrm{~g})$, and a hot ethanolic solution $(20 \mathrm{~mL})$, of dihydrazide of succinic acid ( $2 \mathrm{mmol}, 0.292 \mathrm{~g}$ ), were mixed slowly with constant stirring. This mixture was refluxed at $\sim 75^{\circ} \mathrm{C}$ for $9 \mathrm{~h}$ in presence of few drops of concentrated hydrochloric acid $(\mathrm{pH} \sim 3)$. The reaction mixture was allowed to cool in room temperature, then the cooled solution was poured onto ice cold water. On cooling, white-colored precipitate is separated out, filtered, washed with cold EtOH, and dried under vacuum over $\mathrm{P}_{2} \mathrm{O}_{5}$ yield $50 \%$. Elemental analysis found \% (found atomic mass $420 \mathrm{amu}$ ), C $51.14 \mathrm{H}$ 5.64; $\mathrm{N} 26.53$ for $\mathrm{C}_{18} \mathrm{H}_{28} \mathrm{~N}_{8} \mathrm{O}_{4}$.

2.7. Synthesis of Macrocyclic Adipic Acid Hydrazone Ligand(II). The hot ethanolic solution $(20 \mathrm{~mL})$, of acetylacetone $(2 \mathrm{mmol}, 0.2 \mathrm{~g})$, and a hot ethanolic solution $(20 \mathrm{~mL})$, of dihydrazide of adipic acid $(2 \mathrm{mmol}, 0.348 \mathrm{~g})$, were mixed slowly with constant stirring. This mixture was refluxed at $\sim 75^{\circ} \mathrm{C}$ for $9 \mathrm{~h}$ in presence of concentrated hydrochloric acid $(\mathrm{pH} \sim 3)$. The reaction mixture was allowed to cool in room temperature, then the cooled solution was poured onto ice cold water. On cooling, white-colored precipitate is separated out, filtered, washed with cold EtOH, and dried under vacuum. Yield 55\%. Elemental analysis found \% (found atomic mass $420 \mathrm{amu}$ ), $\mathrm{C} 55.69 \mathrm{H} 6.66$; $\mathrm{N} 22.62$ for $\mathrm{C}_{22} \mathrm{H}_{36} \mathrm{~N}_{8} \mathrm{O}_{4}$.

2.8. Extraction Procedure. Aqueous solutions containing $1.5 \times 10^{-3} \mathrm{~mol} \mathrm{~L}^{-1}$ metal chloride in appropriate buffer were equilibrated with equal volumes of the chloroform and dichloromethane solutions of the ligand $4 \times 10^{-4} \mathrm{M}$ by shaking in a mechanical shaker at $25^{\circ} \mathrm{C}$. Optimum equilibration time was determined for this system. In most cases, distribution equilibrium was attained in less than $180 \mathrm{~min}$ and a shaking time of $120 \mathrm{~min}$. The ionic strength of the aqueous phase was $0.1 \mathrm{M} \mathrm{KCl}$ in all experiments except those in which the effect of ionic strength was studied. After agitation, the solutions were allowed to stand for $120 \mathrm{~min}$. The copper(II) and chrome(III) concentrations of the aqueous phase were determined by FAAS and that of the organic phase from the difference by considering the mass balance. The $\mathrm{pH}$ of aqueous phase was recorded as equilibrium $\mathrm{pH}$.

\section{Results and Discussion}

The preparation of two ligands containing nitrogen and oxygen donor atoms are shown in Scheme 1. The structures of new compounds were characterized by a combination of IR, MS, ${ }^{1} \mathrm{H}$ NMR, and ${ }^{13} \mathrm{C}$ NMR spectral data. Compounds were synthesized according to reported procedures [17].

Ligand(I). The spectrum showed a strong bands at 1715 and $1587 \mathrm{~cm}^{-1}$ in the spectrum of the Schiff base assigned to $v(\mathrm{C}=\mathrm{O})$ of carbonyl and azomethine $v(\mathrm{C}=\mathrm{N})$ vibrations, respectively. An intense band at $3111 \mathrm{~cm}^{-1}$ is due to the -NH-vibrations of the hydrazine group, a broad medium intense band was at $2930 \mathrm{~cm}^{-1}$ due to methylene groups, and the band at $1068 \mathrm{~cm}^{-1}$ is assigned to hydrazinic $v(\mathrm{~N}-$ $\mathrm{N})$ of the ligand [21-25]. In the electron impact spectrum (Figure 1) of the ligand, we confirm the probable formula by showing a peak at $420 \mathrm{amu}$, corresponding to macrocyclic moiety $\left[\left(\mathrm{C}_{18} \mathrm{H}_{28} \mathrm{~N}_{8} \mathrm{O}_{4}\right)\right.$, calculated atomic mass 420$]$. The series of peaks in the range, that is, $37,40,41,42,44,55$, $95,96,97,101,121,132,150,179,201 \mathrm{amu}$, and so forth, may be assigned to various fragments. Their intensity gives an idea of stability of fragments (Figure 1).

In the ${ }^{1} \mathrm{H}$ NMR spectrum the ligand(I) exhibits signals at $2.24 \mathrm{ppm}$ due to $\mathrm{CH}_{3}-\mathrm{C}(6 \mathrm{H}), 2.54$ due to $-\mathrm{CH}_{2}(4 \mathrm{H}), 3.55$ due to $-\mathrm{CH}_{2}-\mathrm{CO}-(8 \mathrm{H})$ and at $5.9 \mathrm{ppm}$ due to $\mathrm{NH}$ protons (Figure 3(a)).

In the ${ }^{13} \mathrm{C}$ NMR spectrum (Figure 3(b)) of ligand(I), and indicated new resonances are $13.80,14.58\left(-\mathrm{CH}_{3}\right), 23.74$, 34.90 $\left(\mathrm{CH}_{2}\right), 110.96,143.99\left(\mathrm{CH}_{2} \mathrm{CO}\right), 151.77(\mathrm{C}=\mathrm{N}), 173.71$ (-CO-NH-).

Ligand(II). The spectrum showed strong bands at 1717 and $1581 \mathrm{~cm}^{-1}$ in the spectrum of the Schiff base assigned to $v(\mathrm{C}=\mathrm{O})$ of carbonyl and azomethine $v(\mathrm{C}=\mathrm{N})$ vibrations, respectively. A broad medium intense bands were at 2959 and $2873 \mathrm{~cm}^{-1}$ due to methyl groups and band at $1136 \mathrm{~cm}^{-1}$ is assigned to hydrazinic $v(\mathrm{~N}-\mathrm{N})$ of the Schiff base [21-25]. 


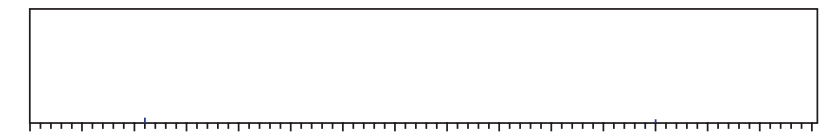

300310320330340350360370380390400410420430440450 UNK-1

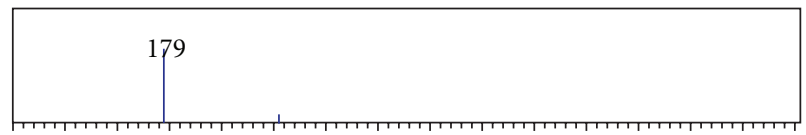

$\begin{array}{llllllllllllllll}150 & 160 & 170 & 180 & 190 & 200 & 210 & 220 & 230 & 240 & 250 & 260 & 270 & 280 & 290 & 300\end{array}$

UNK-1

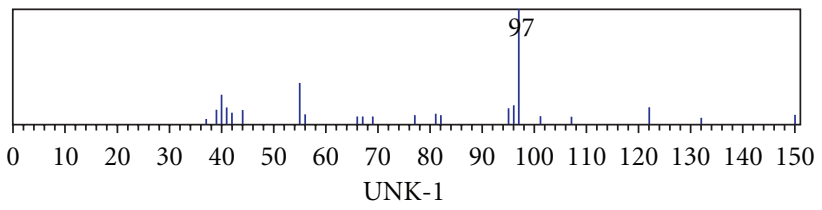

Figure 1: Mass spectra of Ligand(I).

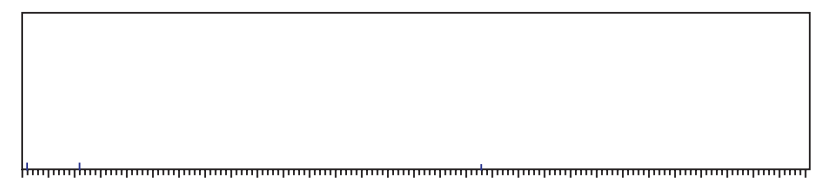
300320340360380400420440460480500520540560580600

UNK-1

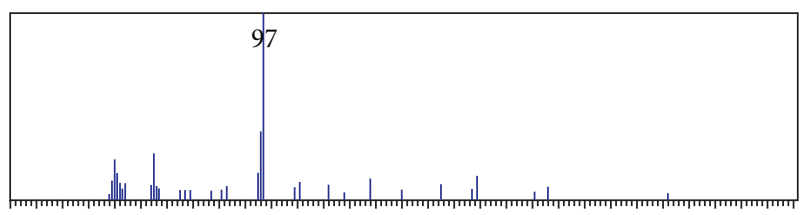

$\begin{array}{llllllllllllllll}0 & 20 & 40 & 60 & 80 & 100 & 120 & 140 & 160 & 180 & 200 & 220 & 240 & 260 & 280 & 300\end{array}$

UNK-1

FIgURe 2: Mass spectra of Ligand(II).
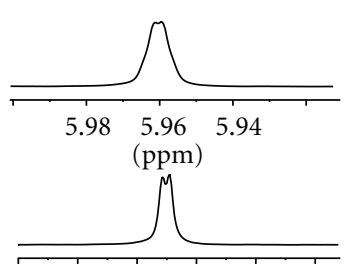

$\begin{array}{llll}2.56 & 2.54 & 2.52 & 2.5\end{array}$

(ppm)

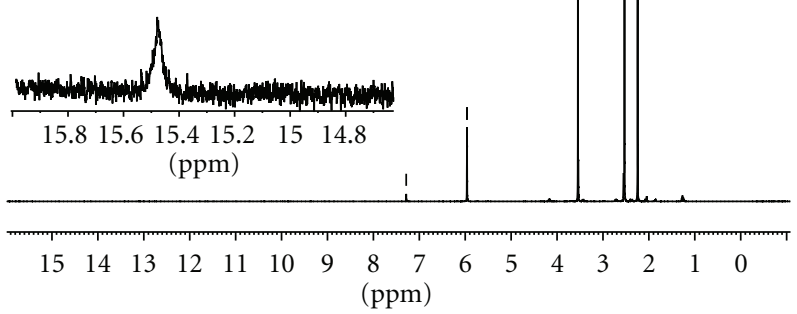

(a)

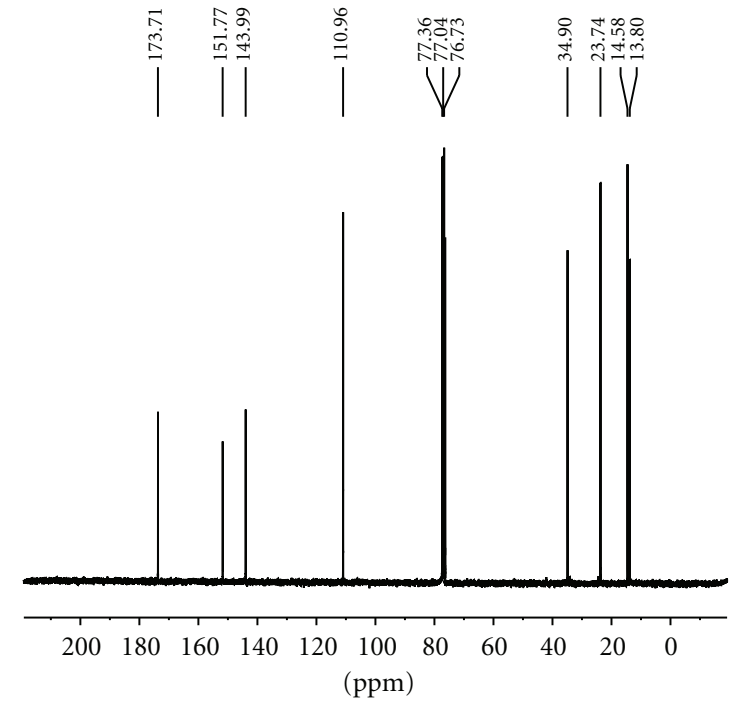

(b)

Figure 3: (a) ${ }^{1} \mathrm{H}$ NMR spectra and (b) ${ }^{13} \mathrm{C}-\mathrm{NMR}$ spectra of Ligand(I). 


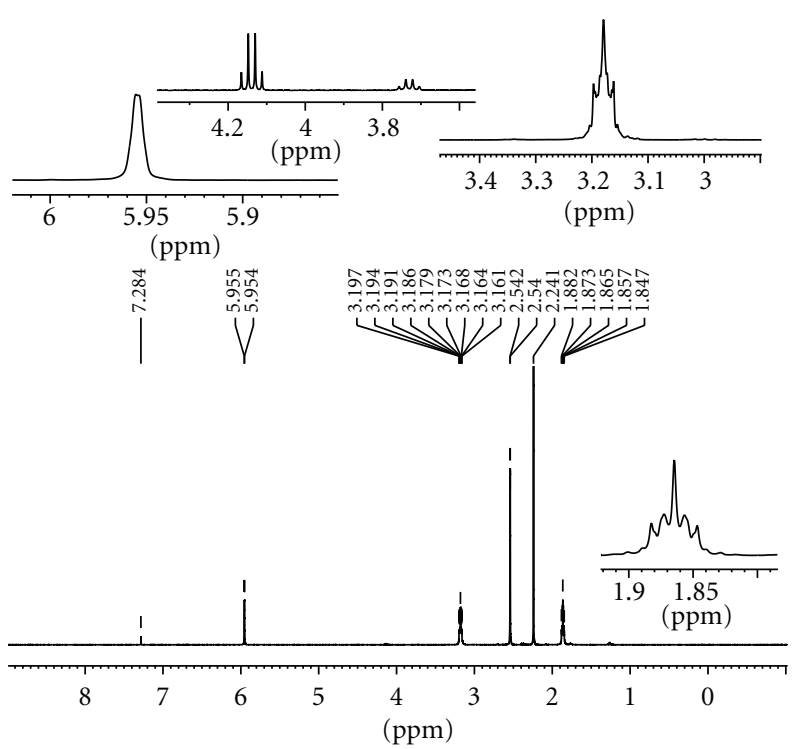

(a)

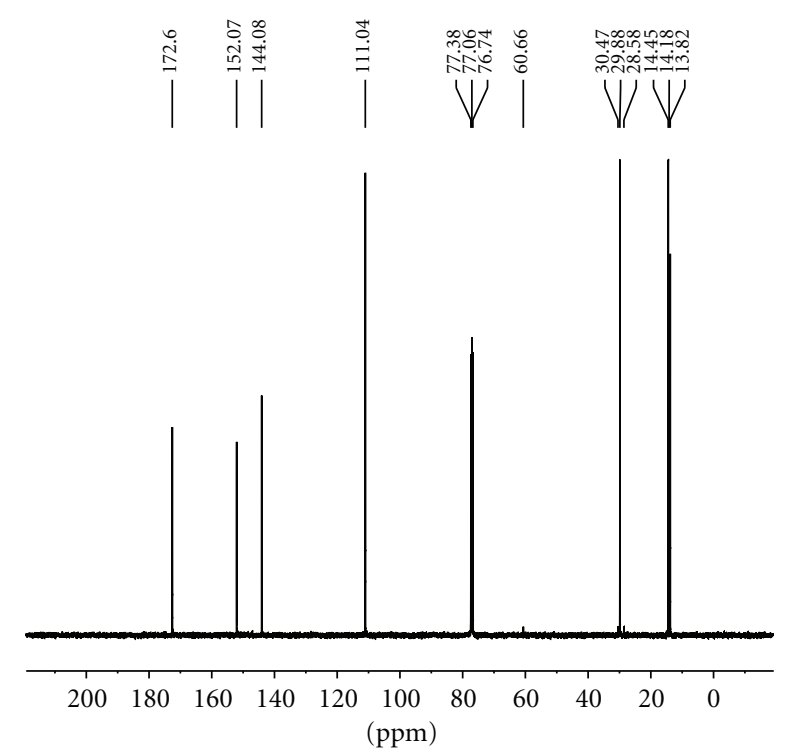

(b)

Figure 4: (a) ${ }^{1} \mathrm{H}$ NMR spectra and (b) ${ }^{13} \mathrm{C}$-NMR spectra of Ligand(II).

In the electron impact spectrum (Figure 2) of the ligand(II), we confirm the probable formula by showing a peak at $476 \mathrm{amu}$, corresponding to macrocyclic moiety $\left[\left(\mathrm{C}_{22} \mathrm{H}_{36} \mathrm{~N}_{8} \mathrm{O}_{4}\right)\right.$, calculated atomic mass 476$]$. The series of peaks in the range, that is, $38,39,40,41,42,43,54,55,56,96$, $97,111,121,138,150,165,179,201,205,251,301,302 \mathrm{amu}$, and so forth, may be assigned to various fragments. Their intensity gives an idea of stability of fragments (Figure 2).

In the ${ }^{1} \mathrm{H}$ NMR spectrum, ligand(II) exhibits signals at 2.24 due to $\mathrm{CH}_{3}-\mathrm{C}(12 \mathrm{H}), 3.17 \mathrm{ppm}$ due to $-\mathrm{CO}-\mathrm{CH}_{2}(4 \mathrm{H})$, $1.8 \mathrm{ppm}$ due to $-\mathrm{CO}-\mathrm{CH}_{2}-\mathrm{CH}_{2}(8 \mathrm{H}), 2.54 \mathrm{ppm}$ due to $\mathrm{CH}_{2}-\mathrm{CN}-(4 \mathrm{H})$, and $5.9 \mathrm{ppm}$ due to $\mathrm{NH}$ protons signal (Figure 4(a)). All these observations support the infrared conclusions.

In the ${ }^{13} \mathrm{C}$ NMR spectrum Figure 4(b) of ligand, indicated new resonances are 13.82, 14.18, 14.45, 28.58, 29.88, $30.47,60.66\left(\mathrm{CH}_{2}\right), 111.04,144.08\left(\mathrm{CH}_{2} \mathrm{CO}\right), 152.07(\mathrm{~N}=\mathrm{C})$, and $172.60(-\mathrm{CO}-\mathrm{NH}-)$.

\subsection{Extraction of Metal Ions with Schiff Bases}

3.1.1. Effect of $p H$ and Solvents on the Extraction of $\mathrm{Cu}(\mathrm{II})$ and $\mathrm{Cr}(I I I)$. To the best of our knowledge, the stability of a transition metal complex with a polydentate chelate ligand in organic phase depends on a range of factors including: number and type of the donor atoms present, the number and size of the chelate rings formed on complexation [24]. In addition, the stability and selectivity of complexations strongly depend on the donor ability, dielectric constant of the solvent, and shape and size of the solvent molecules [26].

In this research, Liquid-liquid extraction experiments were performed to examine the efficiency and selectivity of hydrazones (I) and (II) in transferring s-metal ions $\left(\mathrm{Li}^{+}, \mathrm{Na}^{+}\right.$, and $\left.\mathrm{K}^{+}\right)$and $\mathrm{d}$-metal ions $\left(\mathrm{Cu}^{2+}\right.$ and $\left.\mathrm{Cr}^{3+}\right)$ from aqueous phase into chloroform. The results show that the alkali metals ions are not extracted by hydrazones $(E<3.5 \%)$.

Also the results (Figures 5(a) and 5(b)) show the extractability of $\mathrm{Cu}^{2+}$ and $\mathrm{Cr}^{3+}$ from the aqueous phase into organic phase by macrocyclic hydrazones (I) and (II). It is clear that the extractability results of hydrazones are different for both of the organic solvents. When dichloromethane was used as organic solvent, macrocyclic Schiff bases extracted $\mathrm{Cu}^{2+}$ ion $98 \%$ and $\mathrm{Cr}^{3+} 94 \%$. It is interesting that the percentage of the extraction of the metal ions with both hydrazones (I) and (II) is high. These results suggest that $\mathrm{N}$ donor (the presence of the lone electron pair on the nitrogen atom in hydrazone molecules provides their basic properties) increases the percentage of the extraction of the metal ions.

It can be seen from (Figures 5(a) and 5(b)) that the solvent has an important effect upon the cation extractability. The dielectric constants of dichlor.

omethane and chloroform are 9.1 and 4.8, respectively. Dichloromethane having a high dielectric constants is favored for the extraction of all the metal ions; there are similar results in the literature [27]. On the other hand, the better solvation of the complexes by dichloromethane may be a valuable reason for better extraction.

From the extraction data shown in the figures, it is clear that the ligands which have $\mathrm{N}_{8} \mathrm{O}_{4}$ donor sets show that both of the cationcavity size and the type of binding sites in the ring contribute to the ability of $\mathrm{Cu}^{2+}$ ions and $\mathrm{Cr}^{3+}$ ions binding. As shown in the figures, the copper and chrome extraction is high within the $\mathrm{pH}$ range of 5.2-6, 5-7(Cu), 7$8,7-7.5(\mathrm{Cr})$, respectively. Moreover, transition metals were extracted in the order $\mathrm{Cu}>\mathrm{Cr}$, which are in the same order of decreasing ionic radius.

3.1.2. Composition of the Extracted Species. If only mononuclear species are extracted, under the condition in which 


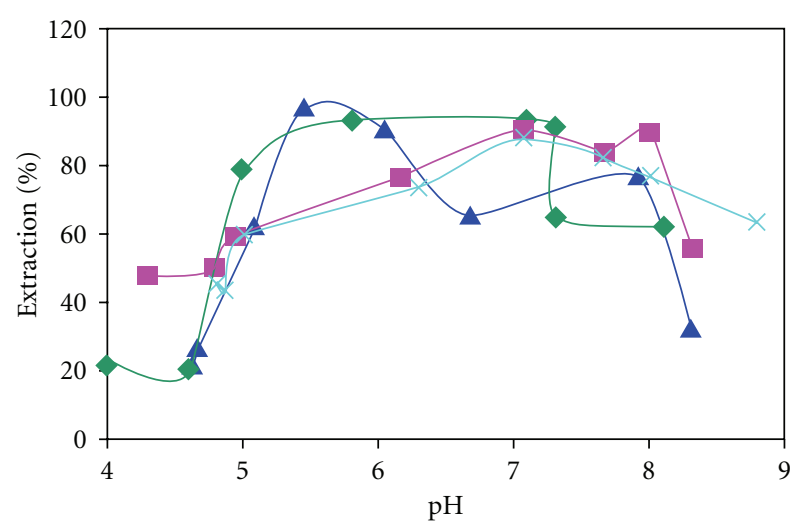

(a)

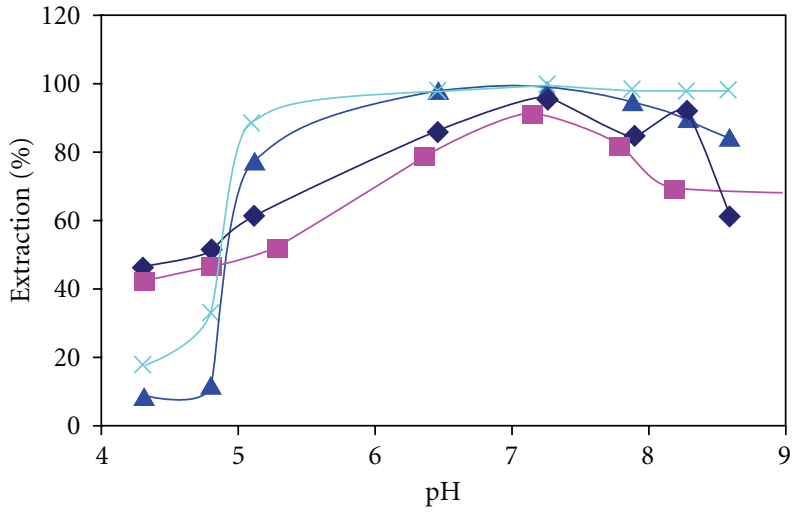

(b)

Figure 5: (a) Effect of $\mathrm{pH}$ on the extraction of $\mathrm{Cu}(\mathrm{II})$ and $\mathrm{Cr}(\mathrm{III})$. [Metal ions] $=1.5 \times 10^{-3} \mathrm{M}$, [Ligand(I)] $=4 \times 10^{-4} \mathrm{M}$ in chloroform and dichloromethane. $(\boldsymbol{\Delta})$ Chloroform $(\mathrm{Cu})(\checkmark)$ dichloromethane $(\mathrm{Cu})(\boldsymbol{\square})$ dichloromethane $(\mathrm{Cr})(\times)$ Chloroform $(\mathrm{Cr})$. (b) Effect of pH on the extraction of $\mathrm{Cu}(\mathrm{II})$ and $\mathrm{Cr}(\mathrm{III})$. [Metal ions] $=1.5 \times 10^{-3} \mathrm{M}$, [Extractant(II)] $=4 \times 10^{-4} \mathrm{M}$ in chloroform and dichloromethane. ( $\left.\mathbf{\Delta}\right)$ Chloroform $(\mathrm{Cu})(\times)$ dichloromethane $(\mathrm{Cu})(\boldsymbol{\square})$ Chloroform $(\mathrm{Cr})(\downarrow)$ dichloromethane $(\mathrm{Cr})$.

chloride does not take part in the distribution equilibrium, the extraction process may be represented by equation

$$
\mathrm{Cu}^{2+}(w)+\mathrm{H}_{n} \mathrm{~L}_{(o)} \rightleftharpoons \mathrm{CuL}_{(o)}+\mathrm{nH}^{+}{ }_{(w)},
$$

where $\mathrm{H}_{n} \mathrm{~L}$ (I) represents the extractant reagent and subscripts $(w)$ and $(o)$ denote the aqueous and organic phases, respectively. The extraction constant of the species $\mathrm{CuL}$ is given by

$$
K_{\mathrm{ext}}=\frac{[\mathrm{CuL}]_{o}\left[\mathrm{H}^{+}\right]_{w}^{n}}{\left[\mathrm{Cu}^{2+}\right]_{w}\left[\mathrm{H}_{n} \mathrm{~L}\right]_{o}}
$$

When $\mathrm{CuL}$ is the only extractable species and the metal is present in the aqueous phase predominantly as the cation $\mathrm{Cu}^{2+}$, the metal distribution ratio $(D)$ and the extraction constant are related by

$$
\log D=\log k_{\text {ext }}+n \mathrm{pH}+\log \left[\mathrm{H}_{2} \mathrm{~L}\right]_{o} .
$$

The effect of $\mathrm{pH}$ on the extraction of $\mathrm{Cu}^{2+}$ and $\mathrm{Cr}^{3+}$ ions from $\mathrm{KCl}$ media of ionic strength $(I=0.1 \mathrm{M})$ has been studied, the logarithm of the $D$ values obtained was plotted against the corresponding $\mathrm{pH}$ values (according to (4) a plot of $\log D$ against $\mathrm{pH}$ at constant $4 \times 10^{-4} \mathrm{M}$ of $\left.\left[\mathrm{H}_{n} \mathrm{~L}\right]\right)$. A straight line with a slope of about 2 was obtained at $I=0.1$ of $\mathrm{Cu}^{2+}$ and $\mathrm{Cr}^{3}$, as shown Figures 6(a) and 6(b). The values represent the number of hydrogen ions released during the formation of metal-ligand complex and intercept $\log \left[\mathrm{H}_{n} \mathrm{~L}\right]+\log K_{\text {ext }}$.

Also Figure 7 shows the evolution of $\log D$ when increasing the concentration of ligands at constant chloride metal concentration with two different organic solvents. As seen from the plots, there is a linear relationship between $\log D$ and $\log [\mathrm{L}]$ org, and the slope should be equal to the number of ligand molecules per cation in the extracted species. The slopes of lines are equal to 0.5 of dichloromethane and chloroform. Therefore, ligands form a $1: 2(L: M)$ complex with $\mathrm{Cu}^{2+}$ for both solvents.
3.1.3. Effect of Ionic Strength of Aqueous Phase. The influence of $\mathrm{KCl}$ in the concentration range of $0.1-1.0 \mathrm{M}$ on the extraction efficiency of $\mathrm{Cu}^{2+}$ was studied in solutions containing $1.5 \times 10^{-3} \mathrm{M} \mathrm{Cu}^{2+}$ and $\mathrm{Cr}^{3+}$ with $4 \times 10^{-4} \mathrm{M}$ ligand in organic phase. The extraction efficiency decreases with increase in ionic strength of the aqueous medium. Taking into account (5), the extraction constant $\left(K_{\text {ext }}^{0}\right)$ at zero ionic strength for this reaction can be correlated with the ionic strength(I) by

$$
\begin{gathered}
\mathrm{Cu}^{2+}{ }_{(w)}+\mathrm{H}_{2} \mathrm{~L}_{(o)} \rightleftharpoons \mathrm{CuL}_{(o)}+2 \mathrm{H}^{+}(w), \\
K_{\text {ext }}^{0}=K_{\mathrm{ext}} \frac{\gamma_{\mathrm{H}^{+}}^{n}}{\gamma_{\mathrm{Cu}^{2+}}}, \\
K_{\mathrm{ext}}=K_{\mathrm{ext}}^{0} \frac{\gamma_{\mathrm{Cu}^{2+}}}{\gamma_{\mathrm{H}^{+}}^{n}} .
\end{gathered}
$$

According to the Debye-Huckel limiting law given

$$
\log \gamma_{ \pm}=-0.5 Z_{i}^{2} \sqrt{I}
$$

The activity coefficient $\left(\gamma_{ \pm}\right)$decreases with increase in ionic strength. At the constant $\mathrm{pH}$, the activity coefficient of $\mathrm{Cu}^{2+}$ decreases as the ionic strength increase, hence $K_{\text {ext }}$ decreases.

\section{Conclusion}

The new synthesized compounds act as tetra dentate Schiff bases. In most cases, these symmetrical compounds were obtained with yield more than $50 \%$ in some cases. Two imines (Schiff bases) were synthesized. We think that these compounds were prepared for the first time. This is confirmed by a precise review of the scientific background concerning this category of compounds. Their structures were identified by spectroscopy methods. The results indicate that $\mathrm{H}_{2} \mathrm{~L}$ (I, II) in organic phase extracts efficiently $\mathrm{Cu}^{2+}$ and $\mathrm{Cr}^{3+}$ in aqueous phase containing $0.1 \mathrm{~mol} \mathrm{~L}^{-1} \mathrm{KCl}$ in the $\mathrm{pH}$ range of approximately $5-7$ and $7-8$, respectively, at $25^{\circ} \mathrm{C}$ and $2 \mathrm{~h}$ stirring. 


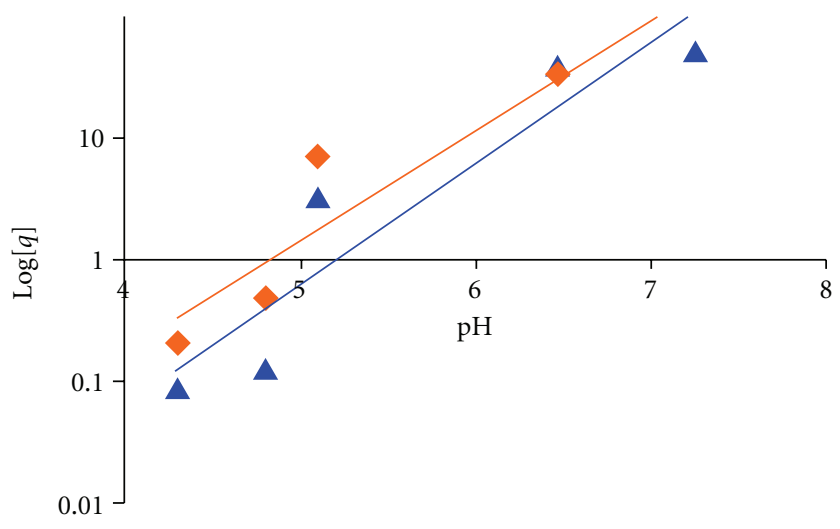

(a)

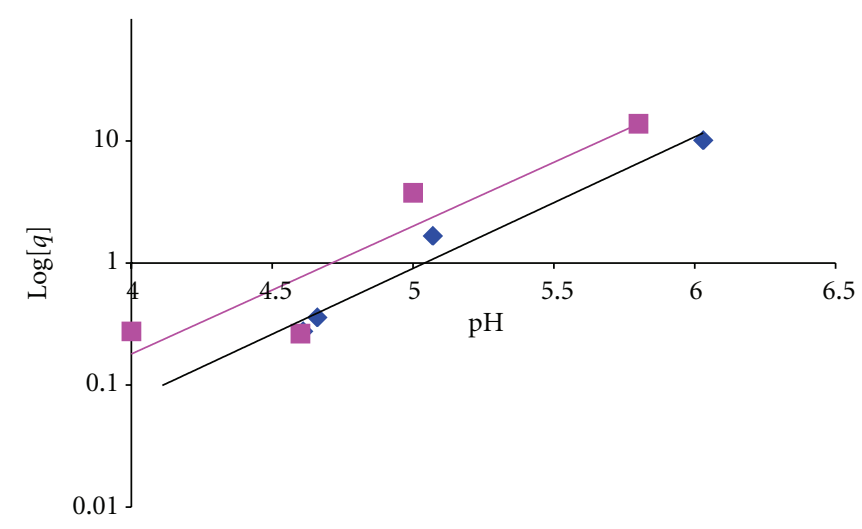

(b)

Figure 6: (a) The plot of $\log D$ versus $\mathrm{pH}$ at constant Ligand(I). constant Ligand(II). ( $)$ chloroform $(\boldsymbol{\Lambda})$ dichloromethane.

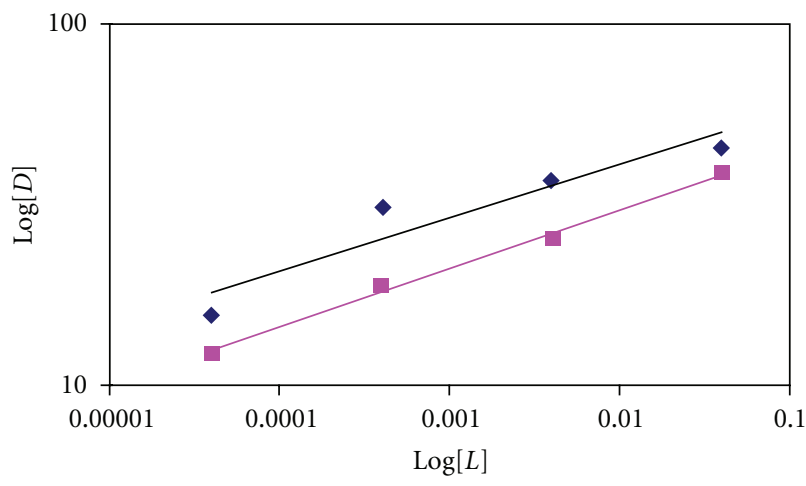

Figure 7: $\log [D]$ versus $\log [L]$ for the extraction of $\mathrm{CuCl}_{2}$ with ligand(I) ( $\square$ ) and Ligand(II) ( $\boldsymbol{\square})$. In chloroform.

\section{Acknowledgment}

The authors are grateful to the Department of Chemistry, Faculty of Science, University of Damascus, Damascus, Syria for supporting of this paper.

\section{References}

[1] J. P. Cornelissen, J. H. Van Diemen, L. R. Groeneveld, J. G. Haasnoot, A. L. Spek, and J. Reedijk, "Synthesis and properties of isostructural transition-metal (copper, nickel, cobalt, and iron) compounds with $7,7^{\prime}, 8,8^{\prime}$-tetracyanoquinodimethanide (1-) in an unusual monodentate coordination mode. Crystal structure of bis(3,5-bis(pyridin-2-yl)-4-amino-1,2,4-triazole)bis $\left(7,7^{\prime}, 8,8^{\prime}\right.$ - tetracyanoquinodimethanido)copper(II)," Inorganic Chemistry, vol. 31, no. 2, pp. 198-202, 1992.

[2] N. Nawar, M. A. Khattab, and N. M. Hosny, "Some metal(II) complexes of o-aminoacetophenone benzoylhydrazone $(\mathrm{AABH})$ : their preparation, characterization and antimicrobial activity," Synthesis and Reactivity in Inorganic and Metal-Organic Chemistry, vol. 29, no. 8, pp. 1365-1384, 1999.
[3] M.-D. Gui, R.-H. Zhang, H. Yan, H.-M. Wang, X.-B. Chen, and S.-J. Zhu, "Synthesis and magnetic and catalytic properties of manganous isonicotinoyl hydrazone complexes," Synthesis and Reactivity in Inorganic and Metal-Organic Chemistry, vol. 28, no. 8, pp. 1381-1391, 1998.

[4] Z. H. Chohan and A. Rauf, "Some biologically active mixed ligand complexes of $\mathrm{Co}(\mathrm{II}), \mathrm{Cu}(\mathrm{II})$ and $\mathrm{Ni}(\mathrm{II})$ with $\mathrm{ONO}$, NNO and SNO donor nicotinoylhydrazine-derived ligands," Synthesis and Reactivity in Inorganic and Metal-Organic Chemistry, vol. 26, no. 4, pp. 591-604, 1996.

[5] S. K. Agarwal, J. Jain, and S. Chand, "Synthetic and antimicrobial studies of hexacoordinated ternary complexes of $\mathrm{Mn}$ (II) and Cu(II)," Asian Journal of Chemistry, vol. 14, no. 1, pp. 489492, 2002.

[6] X. Zhu, C. Wang, W. Dong et al., "Synthesis, structure, and biological activities of the $\mathrm{O}, \mathrm{O}^{\prime}$-diethylphosphorohydrazonothionate ligand and complexes with nickel(II), copper(II), and zinc(II)," Synthesis and Reactivity in Inorganic and MetalOrganic Chemistry, vol. 32, no. 3, pp. 475-487, 2002.

[7] K. A. El-Manakhly, H. A. Bayoumi, M. M. Ezz Eldin, and H. A. Hammad, "Physicochemical and antimicrobial studies of some metal complexes," Journal of the Indian Chemical Society, vol. 76, no. 2, pp. 63-64, 1999.

[8] K. P. Deepa, K. K. Aravindakshan, and F. Suhara, "Synthesis, characterization and antifungal studies of metal, complexes of benzoyl- and salicylylhydrazones of N-methylacetoacetanilide," Asian Journal of Chemistry, vol. 13, no. 2, pp. 513-523, 2001.

[9] A. K. Panda, D. C. Dash, P. Mishra, and H. Mohanty, "Metallo ligands: part V-homo and bimetallic trinuclear complexes of copper(II), nickel(II) and cobalt(II) with 1,8-di-(2'-hydroxyphenyl)-4,5-diphenyl-2,3,6,7-tetrazaoctan-1,3,5,7- tetraene," Indian Journal of Chemistry, vol. 35, no. 10, pp. 848-851, 1996.

[10] M. F. Iskander, L. El-Sayed, N. M. H. Salem, W. Haase, H. J. Linder, and S. Foro, "Synthesis, characterization and magnetochemical studies of some copper(II) complexes derived from n-salicylidene-n-alkanoylhydrazins: X-Ray crystal and molecular structure of bis [monochloro-( $\mu$-n-salicylidenemyristoylhydrazine) ono(-1)] dicopper(II)," Polyhedron, vol. 23, no. 1, pp. 23-31, 2004. 
[11] C. Li, L. Wang, X. Meng, and H. Zhao, "Synthesis, characterization and antitumor activity of benzaldehyde nitrogen mustard picolinoyl hydrazone complexes," Transition Metal Chemistry, vol. 24, no. 2, pp. 206-209, 1999.

[12] G. P. Pokhariyal, B. Lal, and V. K. Rastogi, "Synthesis, pectral and thermal studies of some divalent metal complexes with 8-acetyl-7-hydroxy-4-methyl coumarrin oximehdrazone," Asian Journal of Chemistry, vol. 9, no. 3, pp. 541543, 1997.

[13] F. Bouyagui Tamboura, P. Marcel Haba, M. Gaye, A. Salam Sall, A. Hamady Barry, and T. Jouini, "Structural studies of bis-(2,6-diacetylpyridine-bis-(phenylhydrazone)) and X-ray structure of its Y(III), Pr(III), Sm(III) and Er(III) complex," Polyhedron, vol. 23, no. 7, pp. 1191-1197, 2004.

[14] Y. Inoue, T. Kanbara, and T. Yamamoto, "Preparation of a new receptor for anions, macrocyclic polythiolactam-structure and high anion-binding ability," Tetrahedron Letters, vol. 44, no. 28, pp. 5167-5169, 2003.

[15] P. G. Avaji, C. H. Vinod Kumar, S. A. Patil, K. N. Shivananda, and C. Nagaraju, "Synthesis, spectral characterization, in-vitro microbiological evaluation and cytotoxic activities of novel macrocyclic bis hydrazone," European Journal of Medicinal Chemistry, vol. 44, no. 9, pp. 3552-3559, 2009.

[16] A. A. A. Emara, B. A. El-Sayed, and E. S. A. E. Ahmed, "Syntheses, spectroscopic characterization and thermal behavior on novel binuclear transition metal complexes of hydrazones derived from 4,6-diacetylresorcinol and oxalyldihydrazine," Spectrochimica Acta-Part A, vol. 69, no. 3, pp. 757-769, 2008.

[17] A. A. A. Emara and A. A. A. Abou-Hussen, "Spectroscopic studies of bimetallic complexes derived from tridentate or tetradentate Schiff bases of some di- and tri-valent transition metals," Spectrochimica Acta-Part A, vol. 64, no. 4, pp. 10101024, 2006.

[18] H. S. Seleem, A. A. Emara, and M. Shebl, "The relationship between ligand structures and their CoII and NiII complexes: synthesis and characterization of novel dimeric CoII/CoIII complexes of bis(thiosemicarbazone)," Journal of Coordination Chemistry, vol. 58, no. 12, pp. 1003-1019, 2005.

[19] M. Otomo and I. Nakayama, "Solvent extraction and spectrophotometric determination of palladium(II) with some nitrogen-containing heterocyclic hydrazones in the presence of chloride ions," Microchemical Journal, vol. 25, no. 1, pp. 7581, 1980.

[20] T. Odashima and H. Ishii, "Synthesis and properties of hydrazones from 3-and/or 5-nitro-2-pyridylhydrazine and heterocyclic aldehydes, characterization of their complexes and extraction-spectrophotometric determination of traces of nickel with 2-pyridinecarbaldehyde 3,5-dinitro-2-pyridylhydrazone," Analytica Chimica Acta, vol. 277, no. 1, pp. 79-88, 1993.

[21] M. Robert, X. S. Francis, and J. David, Spectrometric Identification of Organic Compounds, John Wiley \& Sons, New York, NY, USA, 2005.

[22] L. Donald, M. Pavia Gary, and S. Lampman, Introduction to Spectroscopy, Thomson Learning, 3rd edition, 2001.

[23] E. Pretsch, P. Buhlmann, and C. Affolter, Structure Determination of Organic Compounds, Springer, Berlin, Germany, 3rd edition, 2001.

[24] D. P. Singh, R. Kumar, and J. Singh, "Synthesis and spectroscopic studies of biologically active compounds derived from oxalyldihydrazide and benzil, and their $\mathrm{Cr}$ (III), Fe(III) and Mn(III) complexes," European Journal of Medicinal Chemistry, vol. 44, no. 4, pp. 1731-1736, 2009.
[25] S. Chandra and A. K. Sharma, "Nickel(II) and copper(II) complexes with Schiff base ligand 2,6-diacetylpyridine bis (carbohydrazone): synthesis and IR, mass, $1 \mathrm{H}$ NMR, electronic and EPR spectral studies," Spectrochimica Acta-Part A, vol. 72, no. 4, pp. 851-857, 2009.

[26] M. Popovic, "Multinuclear NMR studies of alkali ions in nonaqueous solvents," Pure and Applied Chemistry, vol. 51, no. 4, pp. 101-110, 1979.

[27] B. Ziyadanoğullari, G. Topal, S. Erdoğan, C. Hamamci, and H. Hoşgoren, "Effect of structural modifications of diaza-18crown- 6 on the extractability and selectivity of univalent metal picrates," Talanta, vol. 53, no. 5, pp. 1083-1087, 2001. 


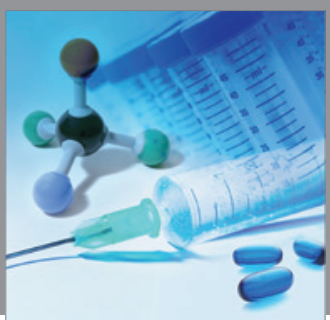

International Journal of

Medicinal Chemistry

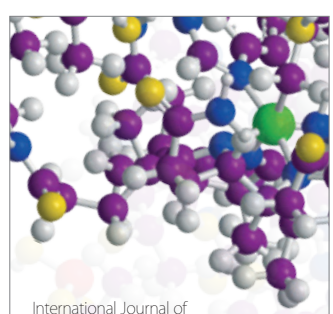

Carbohydrate Chemistry

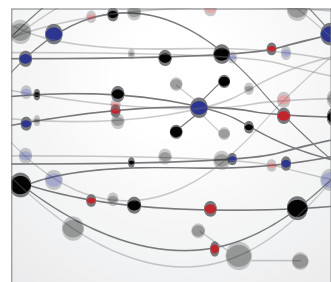

The Scientific World Journal
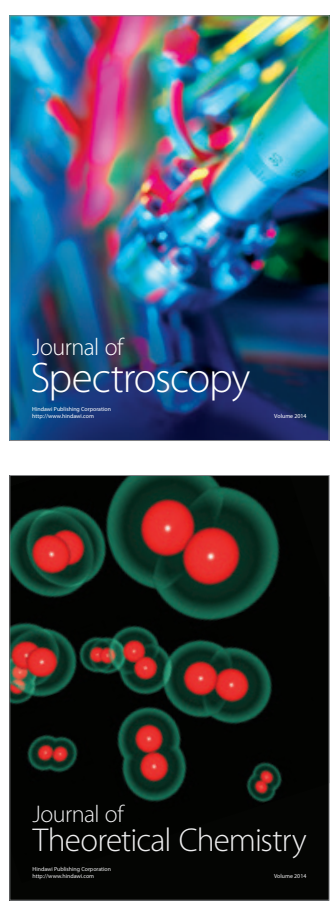
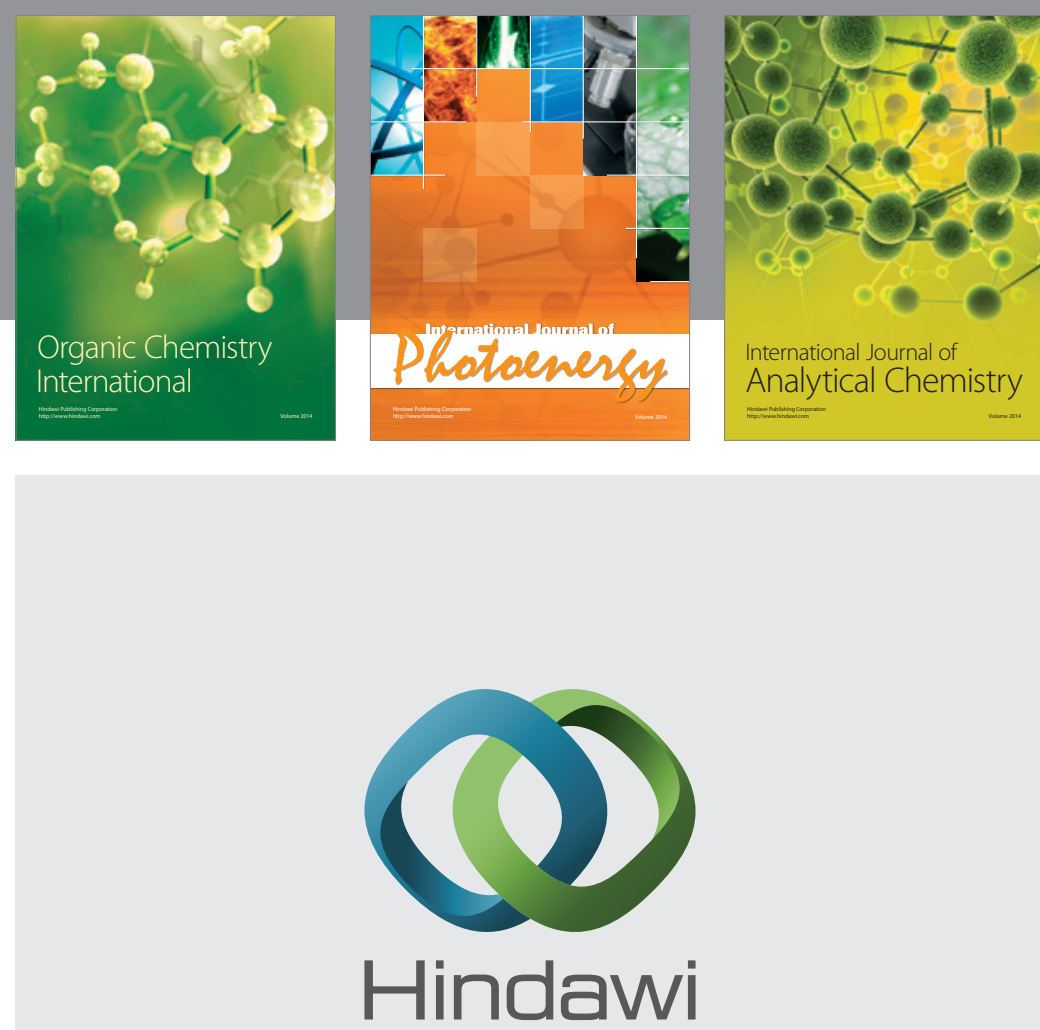

Submit your manuscripts at

http://www.hindawi.com
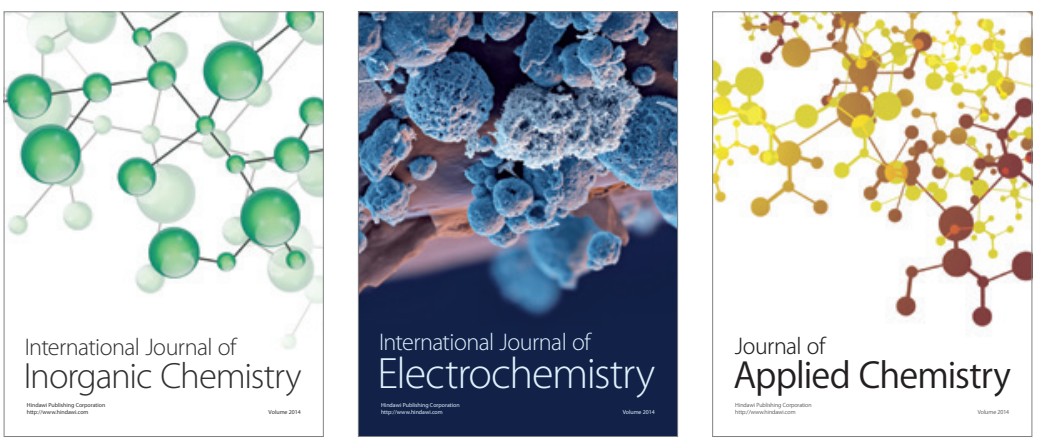

Journal of

Applied Chemistry
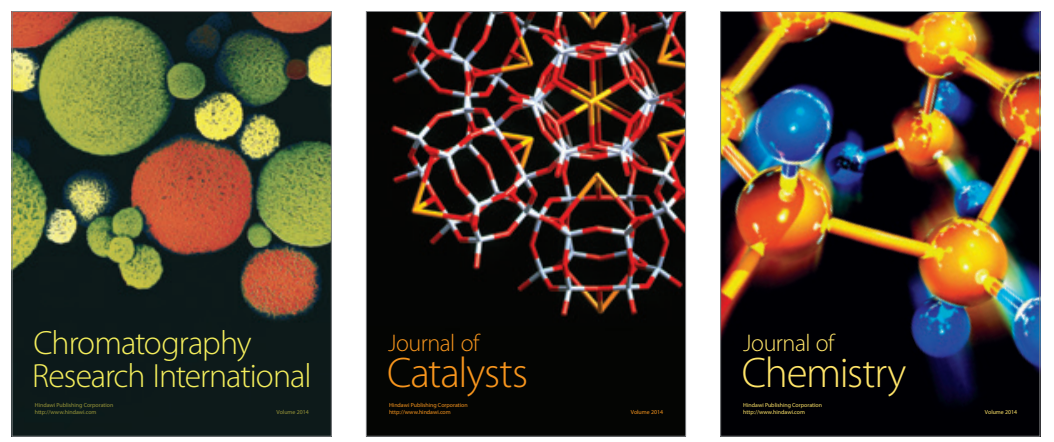
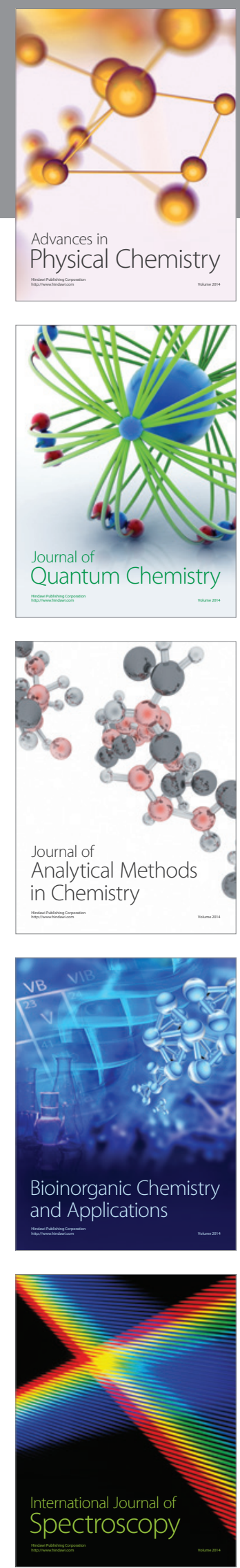